\title{
Sustainability of Small Community Water Systems in Ghana: A Case Study of Navrongo Municipal Area
}

\author{
Melvin-Guy Adonadaga $^{1^{*}} \quad$ Abdul-Latif Umar Mohammed ${ }^{2} \quad$ Samuel Kojo Abanyie $^{1}$ \\ 1. Department of Environmental Science, University for Development Studies, P.O Box 24, Navrongo, Ghana \\ 2. Department of Earth Science, University for Development Studies, P.O Box 24, Navrongo, Ghana
}

\begin{abstract}
Access to safe and clean drinking water is necessary for ensuring good health and the well-being of human societies by reducing the burden of water-related diseases associated with dependence on unsafe water sources. To this end, most communities are provided with boreholes or small community mechanised systems where a centralised water treatment plant is absent. However, issues relating to the sustainability of these systems has become a big challenge to most of these communities mainly due to poor management. This research assessed the operation and maintenance (O\&M) schemes of these water facilities within the Navrongo Municipality of the Upper East Region of Ghana. Structured and semi-structured questionnaires were administered in twenty (20) beneficiary communities to elicit information regarding the involvement of the community members in the general process leading to the provision of the water facility and its management. In addition, the providers of these facilities were interviewed to assess their level of involvement in their maintenance. The survey revealed that community members contributed towards the provision of the facilities, with $68 \%$ of the contributions being in the form of labour. Although $90 \%$ of the respondents admitted to the existence of Water and Sanitation Management Teams (WSMTs), $81 \%$ of them felt that the team members lacked good management skills. $63 \%$ agreed to the need for an upward review of the tariffs in order to meet the cost of O\&M. In addition to providing requisite skills and capacity in community mobilization, WSMTs should be incentivised to ensure effective tariff mobilisation.
\end{abstract}

Keywords: Water systems, small communities, sustainable management, operation and maintenance.

DOI: $10.7176 / \mathrm{JEES} / 9-10-11$

Publication date:October $31^{\text {st }} 2019$

\subsection{Introduction}

Provision of safe water sources and sanitation is a basic requirement and a human right as enshrined in the sustainable development goals (SDGs). An adequate supply of safe and clean water for domestic and other purposes such as agriculture, energy and industry is fundamental to fighting poverty and hunger, and for the health and self-respect of all individuals. The well-being and financial advantages of water supply and sanitation to individuals and families, particularly children, are well recognized globally. Access for the poor is a vital component in enhancing well-being and financial productivity and is in this manner a basic factor of any effort to alleviate poverty. The number of individuals presented with some type of enhanced water supply rose from $79 \%$ (4.1 billion) in 1990 to $82 \%$ (4.9 billion) in 2000. Toward the start of the year 2000, 1.1 billion individuals were without access to improved water supply (UNICEF, 2000). Worldwide, 780 million people do not have access to an improved source of water (WHO, UNICEF, 2012). An estimated 2.5 billion people lack access to improved sanitation (more than $35 \%$ of the world's population) (Prüss-Üstün et al., 2008).

Access to safe drinking water is very important to human health and survival; a healthy community spurs the economic growth of the country. Unfortunately, sustainability of water systems in most parts of sub-Saharan Africa is a major problem. It has been reported that about $35 \%$ of rural water supply systems in sub-Saharan countries are non-functional at any given time (Harvey, 2005). The situation poses a serious economic and public health concern, contributing about $70 \%$ of diseases in most developing countries (WHO, 2010). Poor countries with suitable water systems providing clean water and improve sanitation enjoyed an annual growth of $3.7 \%$ but poor countries without these amenities have their GDP growing at $0.1 \%$. For every $\$ 1$ invested in water and sanitation, there is a profit margin ranging between $\$ 3$ to $\$ 34$ depending on the region and technology applied (CSD report, 2005).

Mindful of this important role of clean drinking water to growth and development, the Government of Ghana through the Community Water and Sanitation Agency (CWSA) has implemented the National Community Water and Sanitation Program (NCWSP) to its pinnacle under the Strategic Investment Plan (SIP) of the CWSA CWSA, 2004). Although the water sector goal of $85 \%$ coverage for urban and $75.43 \%$ for rural by the year 2015 was not achieved, significant progress was made. For instance, the MDG objective of $73 \%$ by the World Community was attained and even outperformed by 4\% in 2015 (GoG, 2007b; World Bank, 2007b; and CWSA, 2008). According to the Ghana Water Company Limited (GWCL), in 2013 urban water supply coverage was about seventy-seven per cent $(77 \%)$ whiles the national coverage for potable water supply in both rural communities and small towns in the country was estimated to be $63.66 \%$ (CWSA Annual Report, 2014). In the case of rural water coverage, the figure for the Upper East region as at 2014 stood at $63.94 \%$, narrowly falling short of the national average of $64.00 \%$ 
(CWSA, 2017).

In spite of all these remarkable improvement of the water sector in Ghana, over 3 million people depend on unsafe sources with about 2000 children under five years old dying annually from diarrhea diseases due to poor water and sanitation (www.wateraid.org, 2016). A major contribution to this is the inability of communities to manage properly the water facilities provided them. For instance, Nyarko (2007) noted that 4 out of 12 newly constructed small town water systems in the Western region of Ghana were non-functional due to issues relating to their management. The sustainable management of these small town water systems is becoming increasingly important as the share of water supply continues to grow in rural and semi-urban areas. For Ghana to see improvement in public health, increased economic growth and reduced poverty among rural communities, water systems must be made sustainable and accessible especially to the rural folks. Concerted effort must be directed towards not only providing these water systems but also making sure the systems are working and serving the rural populace at all times. The active involvement of all stakeholders in this regard is important in achieving the goal of providing safe drinking water for rural communities. To help achieve this goal, this study assessed the performance of existing small community water systems with the aim of making recommendations for their improved management. The following specific objectives were outlined: 1) to determine the level of stakeholders' involvement in the choice of facility; 2) to examine the management modules used in running the small community water systems; and 3) to determine enhanced ways of ensuring sustainability of the facilities so as to improve the livelihood of the communities.

\subsection{Materials and methods}

\subsection{Study Area}

The study was conducted in Navrongo Municipal area, within the Upper East region of Ghana (Fig 1).
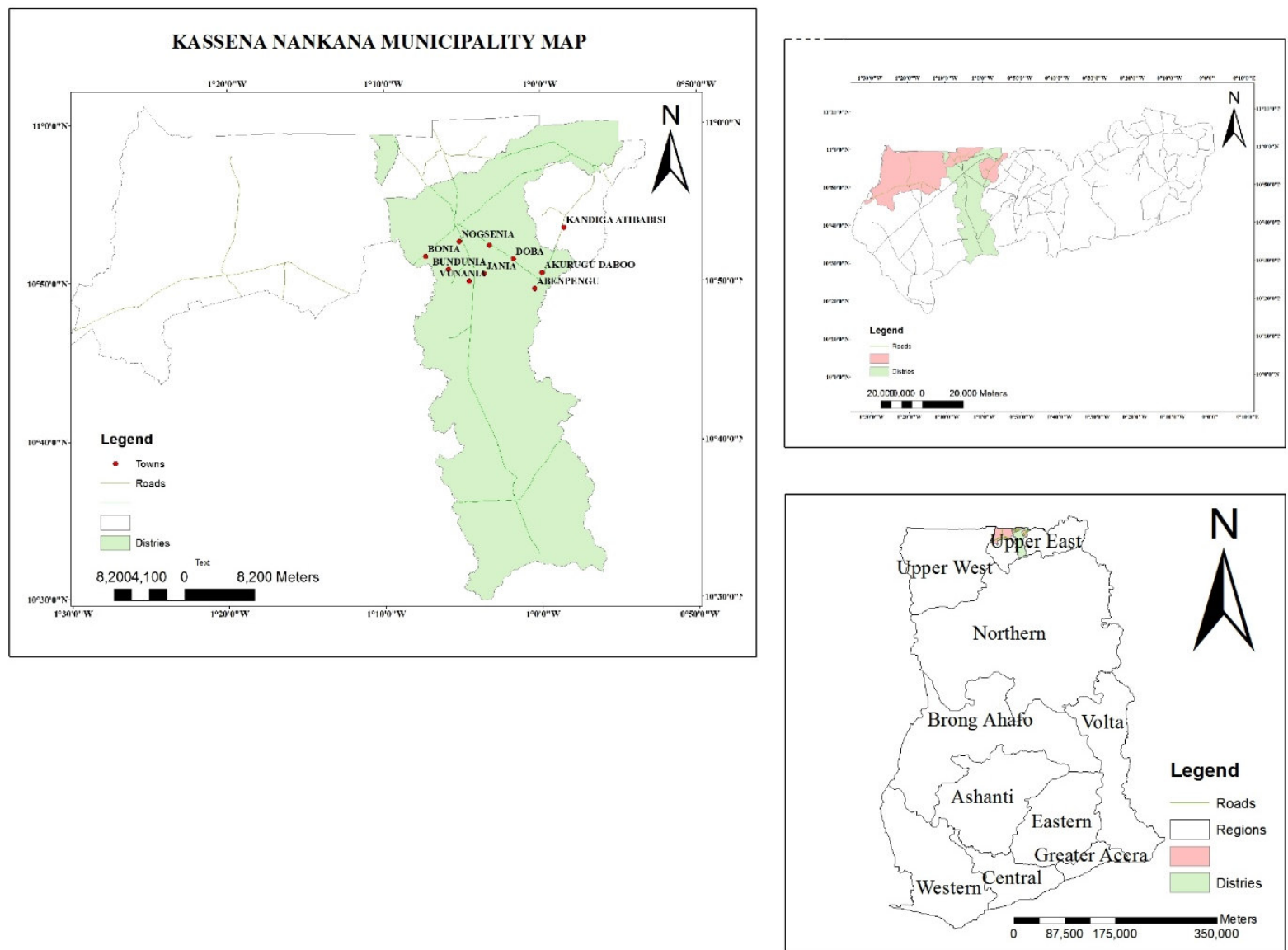

Figure 1. Map showing study area and sampled communities

\subsection{Field surveys}

Twenty communities were selected for the study. Figure 1 above shows the location of the communities included in the study. Interviews and structured questionnaires were administered to the Water and Sanitation Management Teams (WSMTs) in each of the communities in order to assess the sustainability issues considered in the management of the facility. Also, one hundred direct beneficiaries of the water facilities were interviewed to assess 
the impact on their livelihoods among others. In order to ascertain the various considerations that went into choosing a particular facility type, the organizations that provided the water systems were also interviewed. Convenience sampling method was used to collect data from the individual beneficiaries. From each community, questionnaires were administered to either 5 individuals present at the water point at the time of visit to the community or to the nearest five houses to the water point.

\subsection{Results and discussion}

3.1 Background of respondents

The field survey revealed that majority $(68 \%)$ of the respondents are females. The respondents within the age bracket 30-39 were the majority (33\%) while the 40-49 years range had the lowest percentage of $8 \%$. Also, majority of the respondents $(72 \%)$ had formal education, with some even up to the tertiary level Table 1).

Table 1: Table showing educational background of respondents

\begin{tabular}{lc}
\hline Level of Education & Percentage \\
\hline No education & 28 \\
\hline JHS & 23 \\
\hline SHS & 41 \\
\hline Tertiary & 8 \\
\hline Total & 100
\end{tabular}

Although the high percentage of women respondents reported in this study can be attributed to the fact that traditionally women are more engaged in household activities, the relatively high percentage (32\%) of the respondents being men may be indicative of changing values and roles where household chores such as fetching water may be shared. This is a significant departure from opinions commonly held about gender roles in household water management and may reflect the impact of advocacy by civil society organizations for gender mainstreaming in the water sector.

Also, the fact that $85 \%$ of the respondents fall within the active work force indicates a population that is growing and so has the potential to maintain the water sources in a clean and safe state given the needed education and support. Additionally, their interest in the water systems is encouraging as it indicates that they are aware of the health implications associated with dependence on unsafe water sources. This enthusiasm, if properly harnessed and directed, could help reduce the water supply and sanitation disease burden in developing countries (DFID, 2009). The high literacy rate (72\%) within the surveyed communities confirms the results of the population and housing census (2010), and also partly explains the commitment level of the community members as they would have a better appreciation and understanding of the water, sanitation and health nexus. This also has a positive impact on the quality of data gathered from them as they have knowledge about the issues in question (Issah-Bello, 2011).

\subsection{Community contribution}

On the question of contribution towards the provision of the water facility, $68 \%$ of the respondents indicated that they contributed in kind, in the form of labour, while $20 \%$ said they contributed in cash. The respondents admitted that although providing labor gave them a sense of ownership of the project, they saw the cash contribution as more an indication of their commitment to the success of the project. One of the key principles of the National Community Water and Sanitation Policy states that beneficiary communities are obliged to pay between 5-10\% cash contribution toward the capital cost of the water facility. Two main selection criteria for a water facility are cost and technical feasibility. The premise of the policy is that the mobilization of such funds demonstrates a commitment by the community and further serves as an indicator that the water facility may be operated and managed in a sustainable manner (Oheneba-Mensah, 2003). This premise has been confirmed by Odie (2012), who found a significant relationship between community contribution and sustainability of community managed water projects in the Nyando district of Kenya. The study further analyzed UNICEF supported projects in the district and suggested high levels of community contribution to project costs influenced sustainability of the water projects, and concluded that where project management committees were effective, the community-managed projects were sustainable. As determined by the current study, community members understand that their participation and contribution helps to achieve efficiency and provides a sense of ownership and capacity building for purpose of sustainability.

\subsection{Availability and skills of management committee}

On the availability of a management committee, $90 \%$ of the communities said they existed and were working, while the remaining $10 \%$ said they were unaware of their existence. The inability to have management committee in place to see to the operation and maintenance of some of the water facilities in the municipality had led to the neglect of some facilities. The $10 \%$ who had no management committees in place indicated that they usually approach the local government authorities or contact wealthy family members in big cities for assistance whenever 
their systems breakdown. On the question of the management skills of the committee members, only $17 \%$ of the respondents said their WSMTs had good management kills (Table 2).

Table 2: Table showing perception of management skills of the WSMTS

\begin{tabular}{ll}
\hline Management skills & Percentage \% \\
\hline Good Management Skills & 17 \\
Fair Management skill & 81 \\
Poor Management skills & 0 \\
No response & 2 \\
\hline Total & 100 \\
\hline
\end{tabular}

If water projects are to be managed efficiently and sustainably, it is important to promote beneficiary participation in the sense that the main stakeholders should be actively involved in the management of water projects. This is exemplified in the Mozambique's Rural water supply project implementation manual (MIPAR, 2001) which states that water committees must be elected by communities and, for example, collect contributions for the creation of a fund for operation, maintenance, repair and replacement, as well as organizing its management. Having community management in place makes the community solely responsible for operation and maintenance. This goes to confirm the revelation by this study that communities with WSMTs in place did better as compared to those without WSMTs.

Notwithstanding this, most of these WSMTs did not manage their facilities sustainably as confirmed by the non-functioning of most of the facilities. A possible reason for this could be lack of appropriate management skills on the part of the WSMT members. A study of community operated and managed water supplies in Yatta Division of Kenya found that there was a strong relationship between sustainability of community water projects and managerial skills of the committee members (Mwamati, 2007). The lack of managerial skills should partly account for the inability of the boards to organize regular community meetings. In most of the communities, meetings were only arranged when there was a problem with the facility. Another reason that was indicated for the poor performance of the boards and hence the projects is the fact that the work is purely voluntary without any form of remuneration or incentives. As a result, some members of the WSMTs who had received some training, had resigned and been replaced with untrained people. It is undeniable that paying revenue collectors brings with it a sense of duty and the desire to do well which results in a successfully managed water scheme.

\subsection{Tariff structure}

From the survey, it was also revealed that majority (80\%) of the communities had a tariff structure in place, with the community members indicating that they were involved in the tariff fixing. In terms of affordability, only $16 \%$ of the respondents said the tariffs were expensive (Table 3). As to whether they are willing to revise the tariffs to meet the cost of O\&M, $63 \%$ of respondents indicated their willingness, saying that they were not sensitized on the average O\&M cost hence they rather low tariffs fixed. As concluded by Bauman (2006), too often, inadequate levels of finance are collected which reduce the life expectancy of hand pumps due to lack of regular maintenance. Figure 2 below shows some broken down boreholes and mechanized systems due to poor maintenance. However, issues were raised concerning the management of the funds, with $57 \%$ of the respondents complaining of poor management and lack of transparency. For the communities without a tariff structure, they contributed money only when the water system was broken down.

Table 3: Table showing affordability of tariffs

\begin{tabular}{lc}
\hline Affordability of Tariff & Percentage \% \\
\hline Affordable & 24 \\
\hline Moderate & 60 \\
\hline Expensive & 16 \\
\hline Total & 100 \\
\hline
\end{tabular}



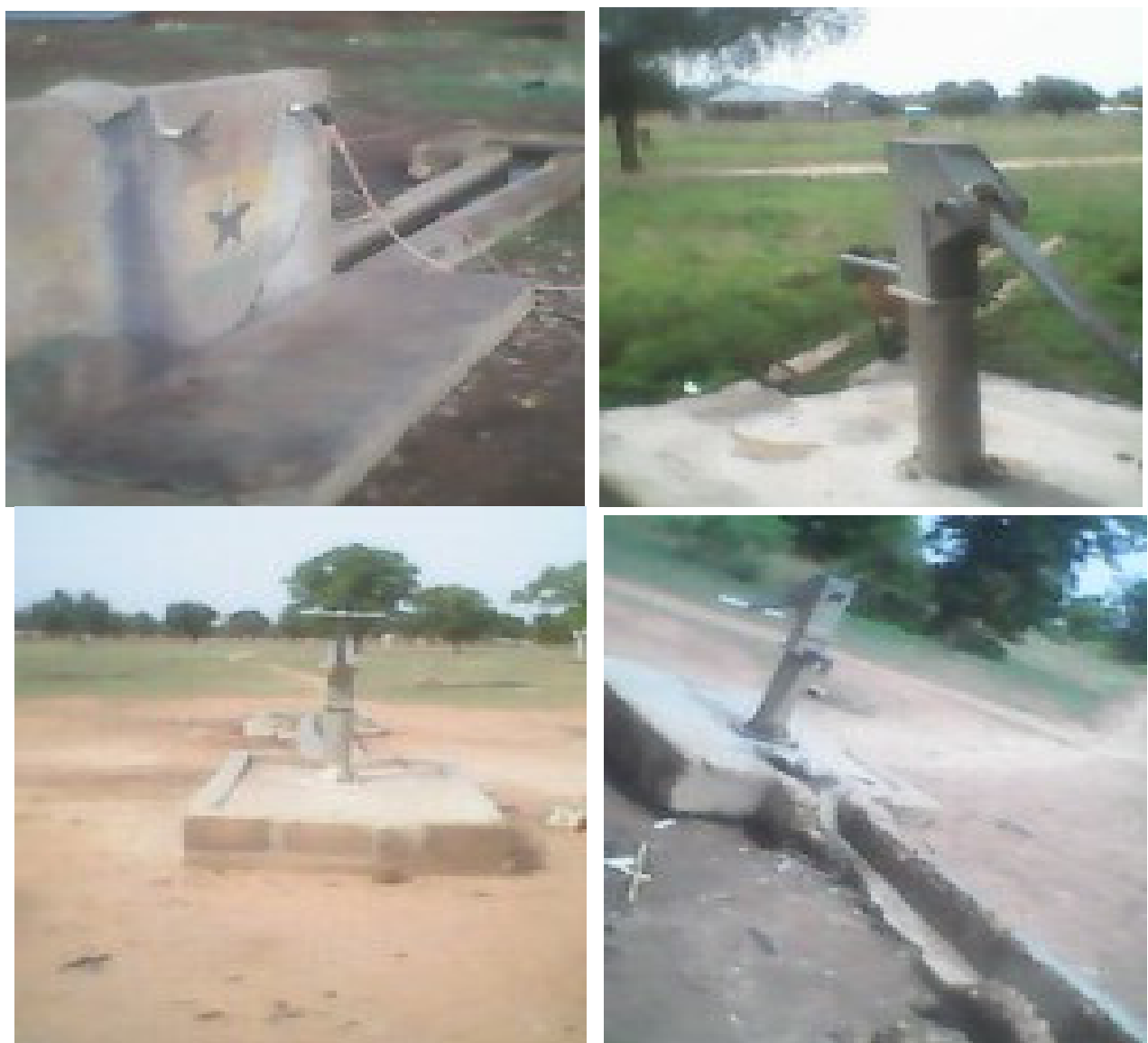

Figure 2. Figure showing poorly maintained water facilities in some of the communities.

Additionally, the study revealed that there was no standard water tariff structure in place in the KassenaNankana Municipality. The amount paid varies depending on the type of facility. For instance, those who used boreholes paid 1 Ghana cedi per month, while those who used mechanized systems paid 3 and 10 Ghana cedis, depending on whether one fetched from a public water point or had a house connection. In order to deliver sustained water supply services and benefits over time, an effective mechanism to administer the water supply tariff in terms of cost sharing practices is crucial (Tadesse et al, 2013). The method of revenue collection makes a difference, with payment per bucket superior to a monthly payment, as it is much simpler to manage and more difficult for users to refuse to pay. Sometimes, there are also social pressures acting on the revenue collectors to exclude friends and family from the obligation to pay (Maranz, 2001). The pay-as-you-fetch system was not practiced at all in the communities surveyed even though it was considered to be one of the most reliable and efficient ways of carrying out O\&M of the facilities.

\subsection{Involvement in choice of technology}

The study also sought to establish whether beneficiary communities were involved in deciding the technologies adopted for their water facilities. To this end, $30 \%$ of the WSMTs confirmed community participation while $70 \%$ indicated that they were not involved in deciding the choice of technology. For example, service providers did not take into consideration the economic status of the communities before deciding the choice of technology. This led to a situation where a very poor community with about 200 people was provided a mechanized borehole instead of a hand pump borehole. Inability of the community members to pay electricity bills resulted in the cutting of power to the pump house, which left the community without any drinking water. A research conducted by UNICEF affirms that at least $94 \%$ of the WSMT members indicated that technology choice and its appropriateness influenced the sustainability of UNICEF supported community-managed rural water supplies at least to a moderate degree, and so recommended an improvement in the participation of beneficiary community in the choice of technology (Tadesse et al, 2013). The kind of technology that cannot serve the best interest of the beneficiaries in terms of the quality and durability may cause further problems for maintenance and thereby negatively affect the sustainability of the project (Carter, 2010). According to literature, suitable technology is fundamental in order to make the water supply system sustainable. The selection of type of technology should consider the availability of spare parts and the socio-economic situation of the community. Communities should participate in the selection of the technology in order to operate and maintain the technology at the village level by the communities 
themselves.

\subsection{Training of WSMTs}

The WSMT members indicated that they were trained at the time the facilities were provided, and have since not received any further training. The community members even wondered if the initial training given to the WSMT members could stand the test of time especially when it comes to fixing major breakdowns. The absence of training programmes could result in the lack of good management practice and hence unsustainable water supply systems. Also, they were asked if they got any post-implementation support from the water providers or any NGOs. Majority of the respondents (95\%) indicated that they did not receive any support, with only one community responding positively. Several research papers; Harvey and Reed (2003), Carter (2009), Carter et al, (1999) and Abrams (1998) have emphasized the important role on-going external support can have in promoting water point sustainability. The most promising support activities found by Whittington et al (2008) were those relating to administrative management and system operation. Indeed, all members of the WSMTs were engaged on voluntary basis.

\subsection{Water systems providers}

The survey revealed that most of the relevant agencies that are into water provision within the municipality had been in operation for about 10 years. Their interventions in the areas of water provision were aimed at addressing the people's poor health conditions associated with lack of water facilities and also to increase accessibility. Unfortunately, these organizations were only aware of the physical presence of one another but unaware of how they work. Hence, there was no co-ordination among the sector players in the municipality. Also, due to lack of uniform or common approach to these interventions, the NGOs tended not to comply with the National Community Water and Sanitation Programme (NCWSP) strategy, although the CWSA in the region was aware of the operations of these NGOs. This creates some confusion and also throws up mixed messages at the community as there is neither a standard practice nor collaboration among the providers. This does not engender sustainability since different organizations operate at different levels.

In terms of approaches to solving the problems of access to safe water and adequate sanitation, there have been two major shifts in recent years. First, at the project level there has been a shift of approach from supply driven to demand led (Addai, 2005). In the areas studied, beneficiaries were of the view that every stage in donor intervention with respect to provision of water facilities must seek to involve them in the entire processes. This simply implies that community members are willing and ever ready to be involved at all levels of development especially in the area of water intervention. All the water systems providers said they involved the community members at all stages of the project. However, this was refuted by a majority of the WSMTs. Involving them in the entire process would guarantee a complete participatory nature of the process; community needs are addressed and gives sense of ownership to the entire community.

The significance of economic sustainability of water and sanitation interventions cannot be overemphasized. For the facilities to continue to serve their intended purpose, there must be adequate arrangements put in place for financial responsibilities towards O\&M of the facilities (Breslin, 2003). As reflected in Table 4 below, economic factors account for $60 \%$ of the sustainability of such projects. This obviously confirms the fact that availability of funds for recurrent costs is often seen as a major factor influencing the sustainable operation of a water supply and sanitation intervention. Without adequate funding, sustainable operation and maintenance is not possible.

Table 4: Table showing nature of interventions and their effects on Sustainability

$$
\text { Nature of Interventions } \quad \text { Percentages \% }
$$

Socio-Cultural factors 15

Economic factors $\quad 60$

Technological consideration $\quad 25$

Total 100

The need for external technical support, including spare parts, to communities was proposed in discussions and evident from communities' experiences. The technical capacity of communities varied significantly. For instance, certain communities were unable to repair their water points because individuals with technical capacity had left the community or they were waiting for technical support from government or local NGO. In other communities, certain WSMT members had successfully repaired water points using their own technical capacity. From the field survey all the water system providers claimed they provided support to the communities after the implementation, but this claim contradicted that of the WSMTs who said they had not received any support from them since they implemented the water projects.

\subsection{Conclusion}

The sustainability of small community water systems within the Upper East region of Ghana was assessed in this study with the aim of identifying weaknesses in their operation and making recommendations for their effective management. The study established that awareness of most community members on the importance of safe and 
clean drinking water as well as their level of involvement in the general operation of the facility was very high. Key challenges identified were the ineffectiveness of the WSMTs of the various communities due mainly to lack of training and the non-remunerative nature of the work. The tariff regimes and the level of support from the providers of the facilities towards their proper management was also identified as a weak link. The involvement of beneficiaries in all the processes of the intervention should be made a pre-requisite for partnership engagement between the provider and the community. This practice would bring about community ownership that would guarantee sustainable use of the facilities. Building adequate skills and capacity of the water and sanitation boards to effectively maintain these water sources is equally important. The social enterprise approach whereby operation and management of these projects is handled by a social entrepreneur should be adopted. In such a scheme, the water user fees charged by the social entrepreneur are regulated by the local authority as to ensure that they are affordable and also allow for the sustainable operation of the facility.

\section{References}

Abrams, L., Palmers, I., Hart, T. (1998).Sustainability Management Guidelines. Department of Water Affairs and Forestry. Pretoria

Addai, E. (2005) Sustainability of Water Projects - Lessons from Kitase/Gyankama, a WaterAid Ghana Briefing Paper.

Baumann, E. (2005). RWSN Strategy Paper: Sustainable Hand pumps. St. Gallen, Switzerland: Rural Water Supply Network.

Breslin, E. (2003). Demand response approach in practice: why sustainability remains elusive. WaterAid discussion document for the Water and Poverty Dialogue at the $3^{\text {rd }}$ World Water Forum Kyoto, Japan. London, UK.

Carter, R. C., Tyrrel, S. F. and Howsam, P. (1999) Impact and sustainability of community water supply and sanitation programmes in developing countries. Journal of the Chartered Institute of Water and Environmental Management, 13:292 - 296

Community Water and Sanitation Agency. (2004). Small Towns Sector Policy. CWSA, Accra, Ghana.

CWSA, (2008). The Community Water and Sanitation Agency Annual Report.

DFID, (2009). MDG Goal 7: Water and Sanitation Factsheet. January, 2009. http://www.dfid.gov.uk/pubs/files/mdg-factsheets/waterfactsheet.pdf [Date accessed: 5/3/17]

GoG, (2007). Small Communities Water and Sanitation Policy. Government of Ghana, Ministry

GoG, (2007b). Update of the Strategic Investment Plan (SIP) and Medium - Term Plan (MTP), Board Draft. Government of Ghana; Ministry of Water Resources, Works and Housing; and Community Water and Sanitation Agency.

Harvey, P. A. and Reed, R. A. (February 10, 2006) Community-managed water supplies in Africa: sustainable or dispensable? Community Development Journal Advance Access 10.1093/cdj/bs1001

Haysom, A. (2006). A Study of the Factors Affecting Sustainability of Rural Water Supplies in Tanzania. Bedfordshire, UK: Cran-field University, p. 54.

Jansz, S. (2011). A Study into Rural Water Supply Sustainability in Niassa Province,

Mozambique, WaterAid

KasenaNankana East Municipality. (2016, August 21). Retrieved February 2, 2017, from http://www.ghanadistricts.com/

Mwamati F.T. (2007). Factors Determining Sustainability of Rural Community Water projects in Kenya. MBA Executive Thesis. Moi University, Eldoret, Kenya

Nyarko, K. B. (2007). Drinking Water Sector in Ghana: Drivers for performance. PhD Dissertation, UNESCO IHE Delft, the Netherlands, July 2007. pp 42-50, 81

Odie, M.S (2012). Community Related Variables Influencing Sustainability ofWater Projects in district. A Case of UNICEF Funded projects Under UNICEF WASH Programme, Kenya. M.A Thesis. University of Nairobi, Nairobi, Kenya

Oheneba-Mensah E. (2003). WaterAid-NGO conference on the policy of community contribution. Community Contributions to Capital Cost of Water Projects in Ghana-Practices and recommendations for Policy Change, Accra, Ghana.

Olmstead, M. (2003). Sustainable water supply for a remote rural community in Mozambique: Oxfam Australia and the Chicano rural development project. The Business of Water and Sustainable Development, 177-186. doi:10.9774/gleaf.978-1-909493-53-7_15

Parry- Jones, S., Reed, R. and Skinner, B. H. (2001) Sustainable hand pump projects in Africa: A literature review. WEDC, Loughborough University, UK

Prüss-Üstün A., Bos, R., Gore, F. \& Bartram, J. 2008. Safer water, better health: costs, benefits and sustainability of interventions to protect and promote health. External World Health Organization, Geneva.

Tadesse, A., Bosona, T., and Gebresenbet, G. (2013). Rural Water Supply Management and Sustainability: The 
Case of Adama Area, Ethiopia. Journal of Water Resource and Protection, 05 (02), 208-221.

UNICEF/WHO JMP report 1999. The WASH Campaign and Vision 21/WSSCC 2000).

UNICEF and WHO (2000) Joint Monitoring Programme Definitions of Indicators http://www.unicef.org/wes/mdgreport/definition.php

Water supply in Ghana. (2016, November 28). Retrieved January 14, 2017, from https://www.wikipedia.org/

WaterAid - Home. (2015, December 5). Retrieved March 19, 2017, from http://www.wateraid.org/

WaterAid, A condensed version of the WaterAid research report "Looking back: Participatory impact assessment of older projects" London, 2001.

Whittington, D. Smith, V. K., Okorafor, A., Okore, A., Liu, JL. \&Mcphail (1992) Giving Respondents Time to Think in Contingent Valuation Studies: A Developing Country Application. Environmental Economic management 2:205-545

World Bank, (2007b). Project Paper on a Proposed Additional Financing Credit to the Republic of Ghana for a Small Towns Water Supply and Sanitation Project in Support of the Second Phase of the CWSP. Report No: $39782-\mathrm{GH})$

World Health Organization and UNICEF. Progress on Drinking Water and Sanitation: 2012 Update.External United States: WHO/UNICEF Joint Monitoring Programme for Water Supply and Sanitation; 2012.

World Health Organization. WHO (2010). Global Water Supply and Sanitation Assessment 2010 Report. Geneva: World Health Organization and the United Nations Children's Fund Publishing 